Revista Brasileira de Agricultura Irrigada v.12, nº.6, p. 3048 - 3057, 2018

ISSN 1982-7679 (On-line)

Fortaleza, CE, INOVAGRI - http://www.inovagri.org.br

DOI: $10.7127 /$ rbai.v12n600961

Protocolo 961.18 - 02/06/2018 Aprovado em 13/01/2019

\title{
PRODUÇÃO E QUALIDADE DE FRUTOS DE PEPINEIRO EM DIFERENTES CONCENTRAÇÕES DE SOLUÇÃO NUTRITIVA
}

\author{
Francisco Ismael de Souza ${ }^{1}$, Nildo da Silva Dias ${ }^{2}$, Adriana Araújo Diniz ${ }^{3}$, Francisco Vanies \\ da Silva Sá ${ }^{4}$, Francisco De Oliveira Mesquita ${ }^{5}$, Osvaldo Nogueira Sousa Neto ${ }^{6}$
}

\section{RESUMO}

O pepino é uma hortaliça bastante consumida in natura e apreciado por ser fonte de vitaminas e minerais. É uma cultura propicia para cultivos em ambiente protegido, todavia poucas pesquisas foram desenvolvidas para melhorar a cultivo dessa espécie em tais condições. Objetivou-se avaliar os efeitos de diferentes concentrações de solução nutritiva na produção e qualidade dos frutos de pepino cultivados em substrato de fibra de coco. $\mathrm{O}$ ensaio foi realizado em ambiente protegido utilizando o delineamento experimental de blocos casualizados, com quatro repetições e cinco plantas por parcela, sendo avaliados cinco concentrações de nutrientes na solução nutritiva $(12,5 ; 17 ; 25 ; 50$ e $100 \%$ da solução nutritiva padrão, cujas condutividades elétricas inicias foram de 1,$0 ; 1,2 ; 1,5 ; 2,3$ e $3,8 \mathrm{dS} \mathrm{m}^{-1}$, respectivamente). Aos 84 dias após o transplantio, os frutos de pepino foram colhidos para avaliação da produção e qualidade dos frutos. A redução da concentração de nutrientes na solução nutritiva padrão de $100 \%$ para $12,5 \%$ não afeta a produção do pepino. As características biométricas peso médio, diâmetro longitudinal, espessura da poupa do fruto e a acidez titulável são reduzidos em função do aumento da condutividade elétrica da solução nutritiva de 1,0 para $3,8 \mathrm{dS} \mathrm{m}^{-1}$. A concentração de nutrientes na solução contendo $67,5 \%$ da solução nutritiva padrão, correspondente a 111,58 $\mathrm{g}$ de $\mathrm{N}-\mathrm{KNO}_{3}, 50,00 \mathrm{~g}$ de P-MAP, 62,44 g de K-KCl, 241,50 g de Ca-CaNO 3 e 120,00 g de $\mathrm{Mg}-$ $\mathrm{MgSO}_{4}$, prove produção satisfatória e frutos de pepino com melhor qualidade físico-química.

1 Eng. Agrônomo, Universidade Federal Rural do Semi-Árido, Campus Mossoró, Mossoró-RN. Email: 1smaelsouza38@hotmail.com

2 Eng. Agrônomo, Doutor em Agronomia, Universidade Federal Rural do Semi-Árido, Campus Mossoró,Mossoró-RN. E-mail: nildo@ufersa.edu.br

3 Eng. Agrônoma, Doutora em Agronomia, Universidade Estadual do Maranhão, Centro de Estudos Superiores de Balsas, Balsas-MA. E-mail: adrisolos@bol.com.br

4 Eng. Agrônomo, Doutor em Engenharia Agrícola, Bolsista do Programa Nacional de Pós-Doutorado, Universidade Federal Rural do Semi-Árido, Campus Mossoró, Mossoró-RN. E-mail: vanies_agronomia@hotmail.com

5 Eng. Agrônomo Doutor em Manejo de Solo e Água, Universidade Federal Rural do Semi-Árido, Campus Mossoró, Mossoró-RN. E-mail: mesquitaagro@yahoo.com.br

6 Eng. Agrônomo, Doutor em Engenharia de Sistemas Agrícolas, Universidade Federal Rural do SemiÁrido, Campus Angicos, Angicos-RN. E-mail: osvaldo.neto@ufersa.edu.br

*Autor Correspondente. 
Palavras-chave: Cucumis sativus L.; cultivo hidropônico; condutividade elétrica; qualidade do fruto.

\title{
YIELD AND POST-HARVEST QUALITY OF CUCUMBER FRUITS IN DIFFERENT CONCENTRATIONS OF NUTRIENT SOLUTION
}

\begin{abstract}
Cucumber is a vegetable crop widely consumed fresh and appreciated by a source of vitamins and minerals. It is a crop suitable for cultivation in protected environment, but little research has been carried out to improve the cultivation of this species under such conditions. Our aim was to evaluate the effects of different concentrations of nutrient solution on yield and fruit production and quality of cucumber grown in coconut fiber substrate. The experiment was conducted in greenhouse utilizing design in randomized block, with four replications and five plants per plot, were evaluated five concentrations of nutrient solution $(12.5 ; 17 ; 25 ; 50$ and $100 \%$ that after dilution resulted in electrical conductivities of 1.0, 1.2, 1.5, 2.3 and $3.8 \mathrm{dS} \mathrm{m}^{-1}$, respectively). At 84 days after transplanting fruits of cucumber were harvested to evaluate yield and fruit quality. The reduction of nutrient concentration in the standard nutrient solution from $100 \%$ to $12.5 \%$ did not affect cucumber production. Biometric characteristics mean weight, longitudinal diameter, fruit storage thickness and titratable acidity are reduced as a function of the electrical conductivity of the nutrient solution from 1.0 to $3.8 \mathrm{dS} \mathrm{m}^{-1}$. The concentration of nutrients in the solution was $67.5 \%$ of the standard nutrient solution, corresponding to 111.58 $\mathrm{g}$ of $\mathrm{N}-\mathrm{KNO}_{3}, 50.00 \mathrm{~g}$ of P-MAP, $62.44 \mathrm{~g}$ of $\mathrm{K}-\mathrm{KCl}, 241.50 \mathrm{~g}$ of $\mathrm{Ca}_{-} \mathrm{CaNO}_{3}$ and $120.00 \mathrm{~g}$ of $\mathrm{Mg}-\mathrm{MgSO}_{4}$, provide satisfactory yield and better physical-chemical quality of cucumber fruits.
\end{abstract}

Keywords: Cucumis sativus L, hydroponic cultivation, electrical conductivity; fruit quality.

\section{INTRODUÇÃO}

O pepino (Cucumis sativus L) pertence à família das cucurbitáceas, a mesma das abóboras, morangas, melancia, melão, chuchu, maxixe, bucha e melão de São Caetano. O seu centro de origem é a Índia, tendo sido posteriormente levado para a China, Filipinas e Ilhas Formosas (MEDEIROS et al., 2010). É uma espécie de clima quente, adaptando-se, porém a temperaturas amenas, principalmente se cultivadas em ambiente protegido (FILGUEIRA, 2013).

$\mathrm{O}$ pepino tem crescido em importância na comercialização de hortaliças, muito apreciado e consumido em todo Brasil (OLIVEIRA et al., 2017). Sendo produto perecível e consumido in natura, na forma de saladas, onde a preocupação com a qualidade nutricional do pepino deve ser mantida em todos os seguimentos envolvidos no processo da produção e comercialização.

Assim, com o desenvolvimento da agricultura nas últimas décadas e a necessidade de aumentar a produtividade e a qualidade dos produtos, o agricultor necessita tecnificar cada vez mais a produção, adequando seu produto e seus sistemas de produção à atual demanda. Este aspecto se acentua quando se trata de horticultura, pois a maioria dos produtores possuem pequena área para cultivo, onde buscam retirar o máximo de rendimento de sua propriedade (RINALDI et al., 2008).

Neste contexto, os cultivos sem solo possibilitam a obtenção de produtos de boa qualidade quando comparados aos sistemas convencionais, devido à maior uniformidade na colheita e eficiência no uso da água para fins de irrigação, além de permitir maior produtividade e melhoria no controle de diversos fatores adversos durante o ciclo produtivo (GENUNCIO et al., 2006; MELO et al., 2012).

O substrato de fibra do coco tem sido amplamente utilizado na agricultura e na indústria. Por sua vez, a fibra da casca do coco como substrato, que ainda não vem sendo amplamente utilizada, poderá se tornar matéria prima 
importante na produção de substratos de boa qualidade para a produção de mudas ou em cultivos sem o uso do solo. A facilidade de produção, o baixo custo e a alta disponibilidade são outras vantagens adicionais apresentadas por este substrato (CASTOLDI et al., 2014).

$O$ cultivo sem solo exige adequação da composição dos nutrientes da solução nutritiva à cultura de interesse. Várias formulações de solução nutritiva são propostas na literatura especializada, porém tem-se necessidade de associar a concentração da solução e o equilíbrio entre os nutrientes com crescimento, desenvolvimento da planta, fisiologia, produção e qualidade de frutos (FERNANDES et al., 2002; OLIVEIRA et al., 2014; OLIVEIRA et al., 2016).

Para se obter alta produtividade das plantas, os nutrientes devem ser fornecidos em quantidades e proporções adequadas em todas as fases do seu ciclo. Portanto, o uso de uma solução nutritiva que atenda às exigências nutricionais da cultura é o primeiro passo para o sucesso do cultivo sem solo (CASTOLDI et al., 2014).

Por outro lado, quando se cultiva em ambiente protegido, o uso excessivo de fertilizantes na solução de nutrientes pode aumentar a salinidade global ou o teor de algum nutriente especifico e prejudicar as plantas. Os teores de nutrientes da solução devem ser suficientes para atender a exigência da cultura, mas não deve ultrapassar valores de condutividade elétrica s acima da tolerada pelas culturas, especialmente aquelas mais sensíveis à salinidade, como é o caso da maioria das olerícolas (SANTANA et al., 2010; OLIVEIRA et al., 2014; DINIZ et al., 2015).

Diante do exposto, objetivou-se avaliar a produção e qualidade dos frutos de pepino cultivado em substrato de fibras de coco sob a influência de diferentes concentrações de nutrientes na solução nutritiva.

\section{MATERIAL E MÉTODOS}

O estudo foi realizado no município de Mossoró-RN, em ambiente protegido, no período de setembro de 2011 a janeiro de 2012. Segundo a classificação de Köppen, o clima da região é do tipo BSwh', com temperatura média anual de $27,4{ }^{\circ} \mathrm{C}$ e umidade relativa média de $68,9 \%$.

$\mathrm{O}$ experimento foi conduzido no delineamento experimental de blocos casualizados, com quatro repetições e cinco plantas por parcela, sendo avaliados os efeitos de cinco concentrações de solução nutritiva.

A solução nutritiva foi preparada seguindo a recomendação de $100 \%$ sugerida por Furlani (1999) para a cultura do pepino. A partir dessa recomendação, foram preparadas as demais concentrações de nutrientes $\left(\mathrm{T}_{1}=12,5 ; \mathrm{T}_{2}=17 ; \mathrm{T}_{3}\right.$ $=25 ; \mathrm{T}_{4}=50$ e $\left.\mathrm{T}_{5}=100 \%\right)$. Para preparar as soluções nutritivas utilizaram-se para cada $300 \mathrm{~L}$ de água de abastecimento (Tabela 1) as seguintes quantidades de macronutrientes $\mathrm{N}-\mathrm{KNO}_{3}$; P-MAP;

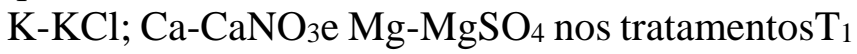
$\left(20,66 ; 9,26 ; 11,56 ; 44,74\right.$ e 22,22 g); $\mathrm{T}_{2}(27,55$; $12,35 ; 15,42 ; 59,65$ e $29,63 \mathrm{~g}) ; \mathrm{T}_{3}(41,33 ; 18,52$; $23,13 ; 89,47$ e $44,44 \mathrm{~g}) ; \mathrm{T}_{4}(82,66 ; 37,04 ; 46,46$; 178,95 e 88,89 g) e $\mathrm{T}_{5}(165,31 ; 74,07 ; 92,51$; $357,78$ e $177,78 \mathrm{~g})$, respectivamente.

Além disso, foram adicionados à solução os seguintes micronutrientes $(\mathrm{M}): 5,88 \mathrm{~g}$ de $\mathrm{B}-\mathrm{H}_{3} \mathrm{BO}_{3}$; 0,80 g de Cu-CuSO $4 ; 3,13$ g de $\mathrm{Mn}-\mathrm{MnSO}_{4} ; 0,29 \mathrm{~g}$ de $\mathrm{Mo}-\mathrm{Na}_{2} \mathrm{MoO}_{4} .2 \mathrm{H}_{2} \mathrm{O}$ e 3,0 g de $\mathrm{Zn}-\mathrm{ZnSO}_{4}$ em um litro de água deionizada. E como fonte de ferro (F) adicionou-se $33,85 \mathrm{~g}$ de $\mathrm{Fe}$ em $1,0 \mathrm{~L}$ de água deionizada. No preparo das soluções nutritivas foram adicionados no tratamento $\mathrm{T}_{1}: 25 \mathrm{~mL}$ de $\mathrm{Me}$ $25 \mathrm{~mL}$ de Fe; $\mathrm{T}_{2}: 33 \mathrm{~mL}$ de $\mathrm{M}$ e $33 \mathrm{~mL}$ de Fe; $\mathrm{T}_{3}$ : $50 \mathrm{ml}$ de $\mathrm{Me} 50 \mathrm{~mL}$ de Fe; $\mathrm{T}$ 4: $100 \mathrm{~mL}$ de $\mathrm{M}$ e 100 $\mathrm{mL}$ de Fe e T5: $200 \mathrm{~mL}$ de $\mathrm{M}$ e $200 \mathrm{~mL}$ de Fe, que após a diluição de todos os nutrientes, a solução nutritiva apresentou $\mathrm{CE}_{\mathrm{a}}$ de $\mathrm{T}_{1}=1,0 ; \mathrm{T}_{2}=1,2 ; \mathrm{T}_{3}=$ 1,$5 ; \mathrm{T}_{4}=2,3$ e $\mathrm{T}_{5}=3,8 \mathrm{dS} \mathrm{m}^{-1}$, respectivamente.

Tabela 1. Caracterização química da água utilizada no preparo das soluções nutritivas.

\begin{tabular}{ccccccccccc}
\hline Fonte & $\mathrm{CE}\left(\mathrm{dS} \mathrm{m}{ }^{-1}\right)$ & $\mathrm{pH}$ & $\mathrm{Ca}^{2+}$ & $\mathrm{Mg}^{2+}$ & $\mathrm{Na}^{2+}$ & $\mathrm{Cl}^{-}$ & $\mathrm{CO}_{3}^{2}$ & $\mathrm{HCO}_{3}^{-}$ & $\begin{array}{c}\mathrm{RAS}^{2} \\
\left(\mathrm{mmmol} \mathrm{L}^{-1}\right)^{0,5}\end{array}$ \\
\hline AA & 0,46 & 8,0 & 0,6 & 0,1 & 5,1 & 1,8 & 0,5 & 3,8 & 8,62 \\
\hline
\end{tabular}

$\mathrm{AA}=$ Água de Abastecimento da UFERSA; $\mathrm{CE}=$ Condutividade Elétrica; $\mathrm{pH}=$ potencial de Hidrogênio; $\mathrm{Ca}^{2+}=\mathrm{Cálcio} \mathrm{Mg}^{2+}=$ Magnésio; $\mathrm{Na}^{+}=$Sódio $\mathrm{Cl}^{-}=$Cloro $; \mathrm{CO}_{3}{ }^{2}-$ = Carbonato $\mathrm{HCO}_{3}{ }^{-}=$Bicarbonato; RAS = Relação de Adsorção de Sódio. 
Cada parcela experimental foi composta por um sistema de cultivo sem solo, constituído por cinco vasos de plástico de $8 \mathrm{~L}$, sendo furados na base para a drenagem da água em excesso e espaçados em 0,5 m entre vasos e 1,0 m entre linhas. Os vasos foram preenchidos com fibra de coco e colocados sobre um suporte (tijolos) a 0,10 $\mathrm{m}$ do nível do solo, para evitar o contato direto do vaso com o piso da estufa.

A cultivar utilizada foi Magnum caipira híbrido F1, pepino do tipo caipira, com frutos verde-claros, estrias brancas e casca lisa, e aptidão para consumo em natura (Tipo mesa). As mudas de pepino (Magnum caipira híbrido F1) foram produzidas em bandejas de 180 células, sendo colocada uma semente de pepino por célula e irrigadas manualmente com água de abastecimento duas vezes por dia durante 13 dias após a semeadura. Aos 13 dias após a semeadura, quando as plântulas apresentaram aproximadamente $10 \mathrm{~cm}$ de altura e dois pares de folhas definitivas, as mudas foram transplantadas para os vasos plásticos com volume de $8 \mathrm{~L}$ contendo substrato de fibra de coco.

$\mathrm{O}$ ambiente protegido utilizado foi do tipo capela, com pé direito de 3,0 m, 12,0 m de largura e $16,0 \mathrm{~m}$ de comprimento, coberto com filme de polietileno de baixa densidade, com aditivo anti UV e espessura de 150 micras, protegido nas laterais com tela preta.

Adotou-se o sistema de irrigação localizada, utilizando-se emissores tipo microtubos de $1,5 \mathrm{~mm}$ de diâmetro interno. O fornecimento de água foi realizado por reservatórios individuais de $300 \mathrm{~L}$, suspensos sobre uma estrutura fixa de ferro, de forma a obter-se uma coluna de água de 1,2 m.

As plantas foram tutoradas verticalmente com auxílio de fitilho e os demais tratos culturais foram realizados nas mesmas condições conforme recomendação de Filgueira (2013). Na parte lateral da área experimental foram plantadas 20 mudas de pepino como bordadura.

A partir dos 84 dias após o transplantio os frutos foram colhidos para avaliação da produção e da qualidade físico-química dos frutos no Laboratório de pós-colheita da Universidade Federal Rural do Semi-Árido (UFERSA). Foi determinado: o número de frutos, pela contagem manual dos frutos emitidos pelas plantas; a massa média dos frutos, obtida pela pesagem individual dos frutos emitidos pela planta, utilizando uma balança analítica, com precisão de $0,01 \mathrm{~g}$; e a produção por planta, referente ao produto da soma do peso total de todos os frutos emitidos pela planta. Para avaliação física, determinou-se a firmeza da casca utilizando um penetrômetro (tipo Fruit Pressure Tester TR) com plunger de ponteira cilíndrica de $8 \mathrm{~mm}$ de diâmetro. $\mathrm{O}$ fruto foi cortado longitudinalmente, sendo obtidas duas medidas diretamente na polpa de ambos os lados do fruto; esses resultados foram obtidos em libras força (lbf) e convertidos para Newton $(\mathrm{N})$, pelo fator de conversão 4,45. A espessura da polpa dos frutos foi determinada utilizando um paquímetro digital. Para avaliar a cavidade do fruto, esses foram cortados transversalmente e realizadas duas medidas em cada lado na região mediana com auxílio de um paquímetro digital. $\mathrm{O}$ diâmetro transversal (equatorial) e longitudinal (polar) dos frutos de pepino foram obtidas utilizando um paquímetro digital.

$\mathrm{Na}$ análise química dos frutos de pepino procedeu-se a determinação do teor de Sólidos solúveis, SS (\%), determinado diretamente no suco homogeneizado (obtido com um processador), através de leitura em refratômetro digital (modelo SAMMAR 852610472) com resultados expressos em ${ }^{\circ}$ Brix e da Acidez Titulável, AT (\% de ácido cítrico), Determinado por titulometria, utilizandose uma alíquota de $1,0 \mathrm{~mL}$ de suco, à qual foram adicionados 49,0 $\mathrm{mL}$ de água destilada e 3 gotas de fenolftaleína alcoólica a $1 \%$, usando-se solução de hidróxido de sódio $(\mathrm{NaOH}) 0,1 \mathrm{~N}$, padronizada com biftalato de potássio, como titulante (IAL, 2008).

Os dados foram submetidos à análise de variância, as médias dos resultados foram comparadas pelo teste $\mathrm{F}(5 \%)$ e submetidos a análise de regressão com o auxílio do programa 'SISVAR' (FERREIRA, 2014).

\section{RESULTADOS E DISCUSSÃO}

O aumento da concentração de nutrientes na solução nutritiva influenciou significativamente o número de frutos por planta de pepineiro, sendo constatada uma variação média de 7,5 a 10 frutos por planta, com a maior emissão de frutos observadas nas plantas cultivada na solução nutritiva padrão (100\%) (Figura 1A). Esses valores estão abaixo da variação de 11,4 a 14,0 frutos planta $^{-1}$ de pepino (cultivar Aodai) obtida em 
experimento realizado por Fernandes et al. (2002) em cultivo hidropônico colhido dos 42 aos 87 dias após ao transplantio (DAP), o que pode estar relacionado as características da cultivar.
A

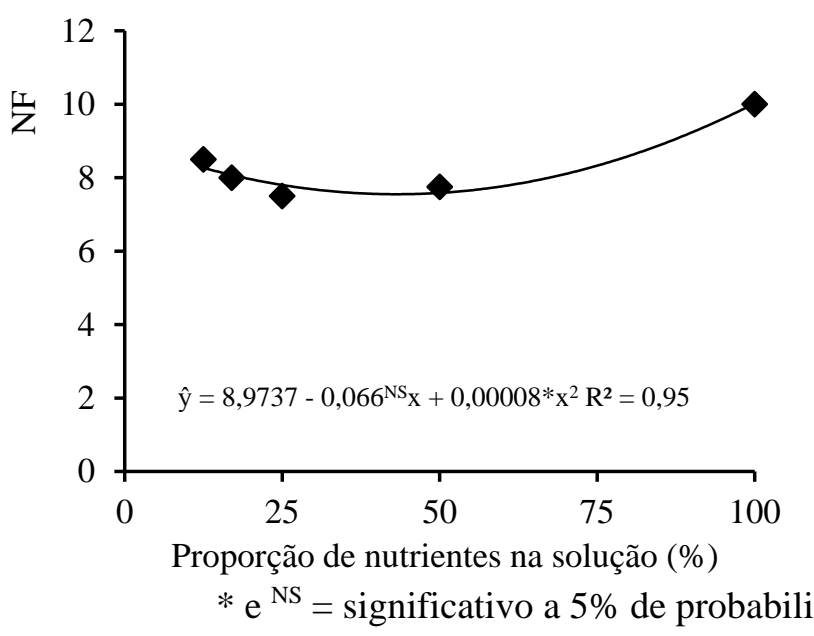

B

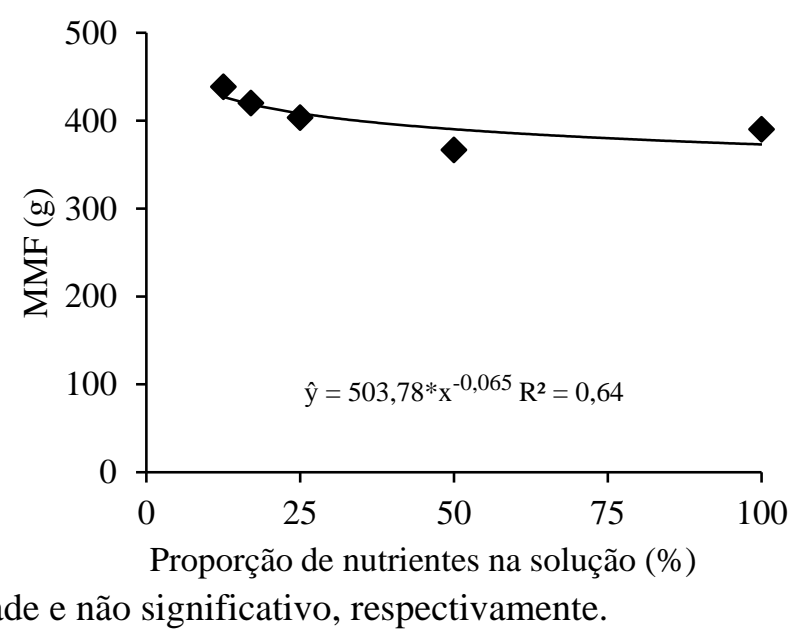

Figura 1. Número de frutos, NF (A) e massa média de frutos, MMF (B) de pepino em função de proporções de nutrientes na solução nutritiva.

A massa média dos frutos (MMF) de pepino foi reduzida em função do aumento da concentração de nutrientes na solução nutritiva (Figure 1B), sendo registrados valores de MMF oscilando entre 326,48 a 438,44 g. Essa redução foi inversamente proporcional a emissão de frutos por plantas, indicando que as plantas mesmo cultivadas com maior disponibilidade de nutrientes, não apresentam capacidade de elevar a fotossíntese liquida suficiente para produzir um grande número de frutos, sem afetar a massa média do fruto, apresentando com isso, uma baixa relação fonte:dreno (LINS et al., 2016).

Os valores obtidos para MMF no presente trabalho foram superiores a médio obtida por Sediyama et al. (2012) (146,74 g por fruto) para o pepino tipo Japonês cultivado em ambiente protegido sob adubação orgânica com esterco bovino. Além disso, as médias obtidas foram superiores a variação encontrada por Dias et al. (2010) em melão rendilhado em sistema hidropônico de cultivo, os quais registraram peso médio de frutos oscilando de 130,1 a 380,4 g por fruto com CE da solução nutritiva de $5,5 \mathrm{dS} \mathrm{m}^{-1} \mathrm{em}$ relação ao tratamento testemunha.

A produção de frutos por planta não foi afetada significativamente pelas concentrações de nutrientes na solução, obtendo produções entre 2.676 e $3.382 \mathrm{~kg}$ planta $^{-1}$. Esses valores de produção por planta se aproximam da variação obtida por Fernandes et al. (2002), em pepineiro (cultivar Aodai) em sistema hidropônico de cultivo. A ausência de efeito significativo das diferentes concentrações de nutrientes na solução nutritiva é indicativo, que a cultivar de pepino Caipira apresenta menores exigências nutricionais em relação as demais cultivares pepino, desempenhando produção satisfatórias mesmo em baixas condições de disponibilidade de nutrientes.

Para a espessura da polpa foi constatado comportamento quadrático, sendo a maior espessura de $14,65 \mathrm{~cm}$ obtida na concentração de $24,67 \%$, com o incremento de nutrientes na solução, a partir desta concentração, houve redução na espessura da polpa do pepino (Figura 2A). Essa inferioridade nas concentrações mais elevadas evidencia que com o aumento dos fertilizantes da solução nutritiva diminuiu drasticamente a espessura da polpa em detrimento do incremento da concentração salina da solução nutritiva. No entanto, os valores de espessura da polpa obtidos no presente trabalhos foram superiores aos obtidos por Fernandes et al. (2002) ao avaliarem o efeito de soluções nutritivas preparadas com diferentes conjuntos de fontes de nutrientes na qualidade de frutos que obtiveram $2,3 \mathrm{~cm}$ de espessura da polpa de frutos de pepino cv. Aodai hidropônico aos 42 DAT. 
A

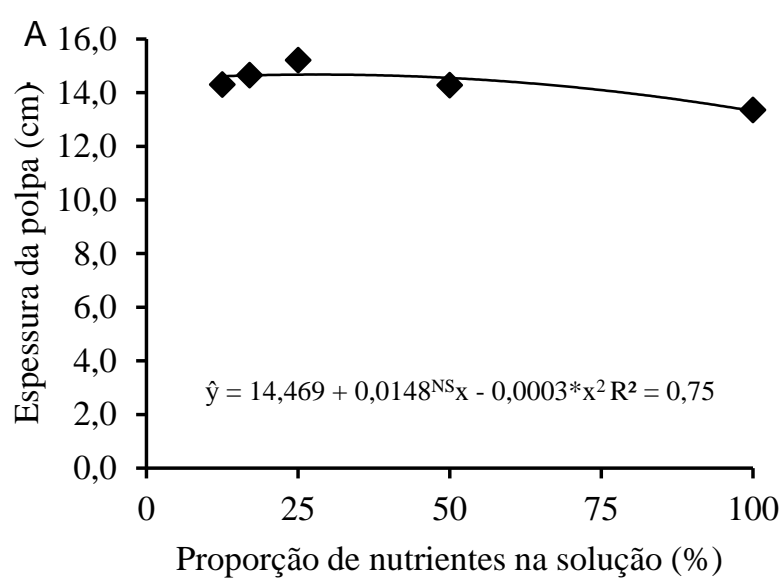

$\mathrm{C}$

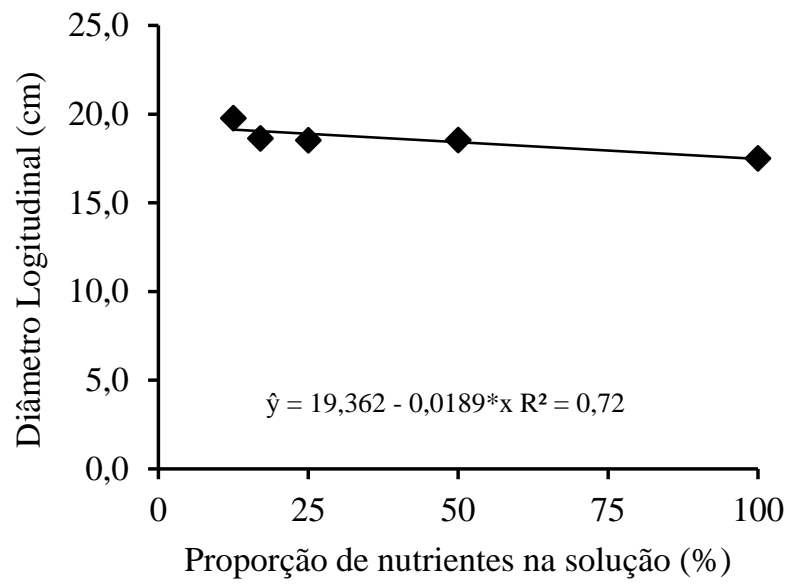

B

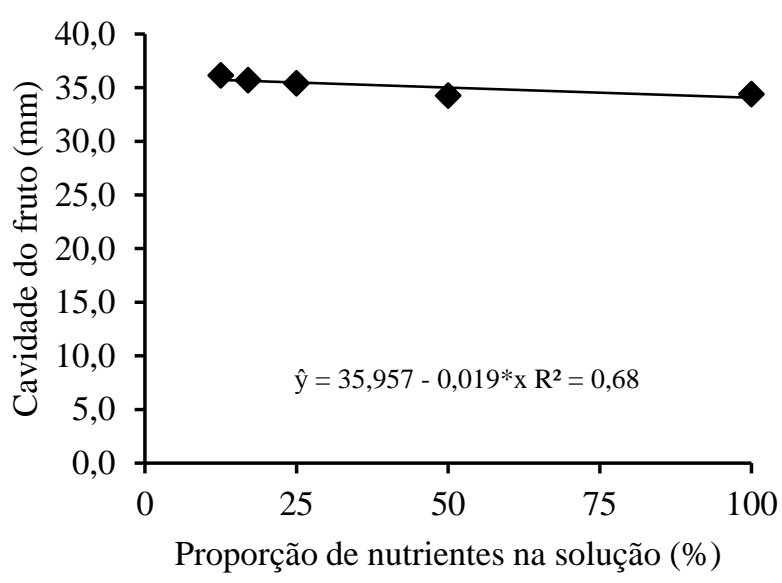

$\mathrm{D}$

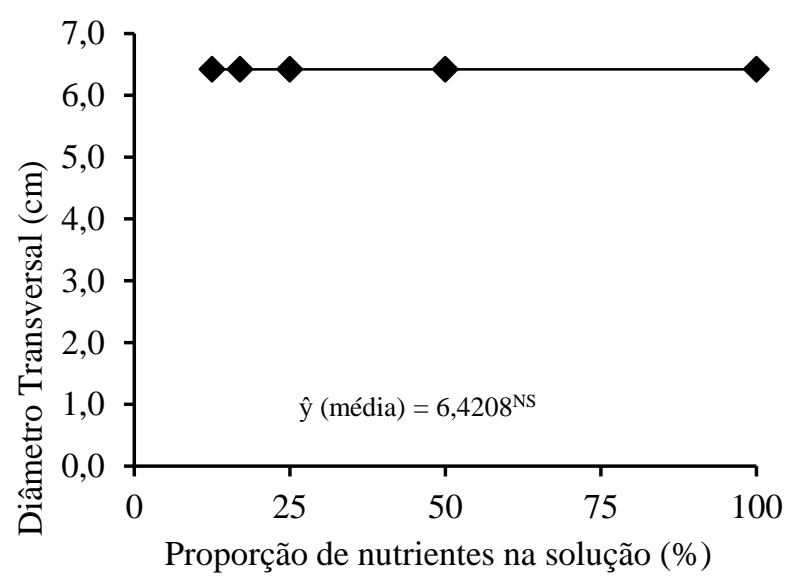

$\mathrm{E}$

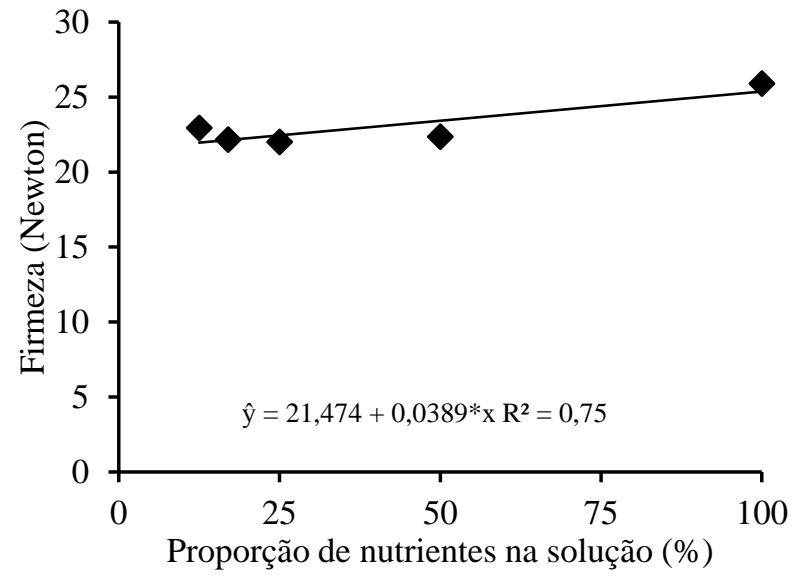

$* \mathrm{e}^{\mathrm{NS}}=$ significativo a $5 \%$ de probabilidade e não significativo, respectivamente.

Figura 2. Espessura da polpa (A), da cavidade (B), diâmetro longitudinal (C), diâmetro transversal (D) e firmeza (E) de frutos de pepino em função de proporções de nutrientes na solução nutritiva.

O efeito da salinidade na solução nutritiva é evidenciado com os níveis mais elevados de íons de sais ou fertilizantes (Figura 2A), e, consequentemente, com uma maior condutividade elétrica, as plantas apresentaram menor espessura da polpa, enquanto que nos níveis mais baixos de salinidade os frutos tiveram uma maior expressividade na espessura da polpa. Vale salientar, ainda, que a maior espessura da polpa é desejável, pois indica maior aceitação em virtude do aumento de massa, da produção e consequentemente melhora na qualidade do fruto.

A espessura da cavidade do fruto foi reduzida linearmente pelo aumento da concentrações de 
nutrientes da solução nutritiva, sendo constatado reduções de $1,7 \mathrm{~mm}$ entre as concentrações de 12,5 e $100 \%$ da solução (Figura 2B). Verificou-se também, que, os maiores valores para a espessura da polpa, foram obtidos no tratamento de $12,5 \%$ de nutrientes na solução, que corresponde a salinidade

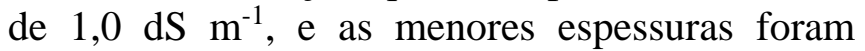
observadas na solução concentrada à 100\% (Figura 2A).

Desse modo a redução da cavidade do fruto pode estar relacionado com a redução da espessura da polpa, ocasionada pelo aumento da condutividade elétrica da água, provavelmente, tenha ocorrido em virtude do aumento dos níveis de nutrientes na solução para concentrações partindo de $12,5 \%$ para até $100 \%$, o que corresponde, respectivamente, a valores de condutividade elétrica variando de 1,0 até $3,8 \mathrm{dS} \mathrm{m}^{-}$

1. Nesse sentido, são comuns alterações morfofisiológicas das plantas que, resultem em reduções desses parâmetros bem como no seu crescimento e produção das plantas (OLIVEIRA et al., 2014; DINIZ et al., 2015, SÁ et al., 2015).

O diâmetro longitudinal dos frutos de pepino também foi reduzido linearmente pelo aumento da concentração de nutrientes na solução nutritiva, averiguando uma redução de $8,67 \%$ no comprimento do fruto em função da aumento da concentração de nutrientes na solução de $12,5 \%$ para $100 \%$ (Figura 2C). Essa situação pode ser verificada em função do aumento salino das respectivas soluções em função do acréscimo com fertilizantes na solução. Em termos gerais, os valores obtidos para diâmetro longitudinal até a concentração de $50 \%$ de nutrientes em solução, são superiores os $18,1 \mathrm{~cm}$ de comprimento obtidos por Fernandes et al. (2002) em frutos de pepino cv. Aodai hidropônico. Estão dentro da faixa de comprimento na ordem de 16,39 à $24,75 \mathrm{~cm}$ registradas por Sediyama et al. (2012) em frutos de pepino cultivado em solo em ambiente protegido com esterco bovino e húmus, com valores da ordem de 16,39 à $24,75 \mathrm{~cm}$. Porém, foram inferiores as variação observada por Pedrosa et al. (2011) que foi de 21,50 a $22,94 \mathrm{~cm}$ em frutos de pepino $\mathrm{cv}$. Aodai, cultivadas em solução nutritiva, com diferentes relações $\mathrm{N}: \mathrm{K}$.

$\mathrm{O}$ diâmetro transversal ou largura dos frutos não foi influenciada significativamente pela variação na concentração de nutrientes na solução, apresentando um diâmetro médio 6,42 cm (Figura
2D). O valor médio obtido no presente trabalho foi superior a faixa de 4,90 a $5,42 \mathrm{~cm}$ observada por Fernandes et al. (2002) e Pedrosa et al. (2011) em pepino (cv. Aodai) em cultivo hidropônico. E aos $2,43 \mathrm{~cm}$ observados por Sediyama et al. (2012) ao avaliarem o pepineiro do tipo Japonês com húmus de minhoca em ambiente.

A firmeza da casca foi incrementada linearmente com aumento da concentração de nutrientes na solução nutritiva, sendo verificado um incremento de 0,97 Newton para cada aumento de $25 \%$ na concentração de nutrientes na solução, com o maior índice de firmeza 25,36 Newtons obtidos na solução nutritiva padrão (100\%) recomendada por Furlani (1999). Esses valores foram superiores a variação obtida por Pedrosa et al. (2011) que foi de 0,58 a 0,69 $\mathrm{N}$ em pepino (cv. Aodai), cultivadas em solução nutritiva, com diferentes relações N:K. Por outro lado, para Medeiros et al. (2010), ao estudarem a tolerância do pepino à salinidade sobre propriedades físicoquímicas dos frutos reportaram que a variável firmeza da casca foi influenciada pelos níveis de salinidade estudados e que com o incremento da salinidade observou-se um decréscimo dos valores médios de firmeza da polpa.

O excesso de sais no solo ocasiona uma menor absorção de água e nutrientes, consequentemente, um maior período de desenvolvimento vegetativo e ponto de colheita dos frutos, ou seja, frutos submetidos a este "stress" permanecem mais tempo na planta, deliberando assim, uma excessiva atividade metabólica (MEDEIROS et al., 2010).

Dias et al. (2010) avaliaram a qualidade de frutos de melão irrigado com solução salina e, verificaram efeito reduzido da salinidade da solução nutritiva sobre o crescimento e a produção do melão ocorrem devido à alta capacidade de absorção hídrica do substrato de fibra de coco utilizado com meio de crescimento (cerca de $85 \%$ de umidade) que, provavelmente, reduziu os efeitos osmóticos (potencial matricial inerte) e de toxicidade iônica dos sais presente na solução nutritiva e, consequentemente, os efeitos negativos da salinidade sobre o crescimento das plantas.

A acidez titulável variou de forma quadrática em função do incremento de nutrientes na solução nutritiva, com o maior índice de acidez $(0,23 \%)$ observado sob a concentração de $25 \%$ da solução nutritiva padrão, com posteriores decréscimos na 
acidez (Figura 3A). Esse comportamento difere do apresentado por Medeiros et al. (2010) em cultivo com pepino (híbrido Hokushin), utilizando dois manejos de fertirrigação e seis níveis iniciais de salinidade do solo em ambiente protegido verificaram que a variável acidez total titulável apresentou diferença significativa em seus valores médios para os seis níveis de salinidade assumindo

A

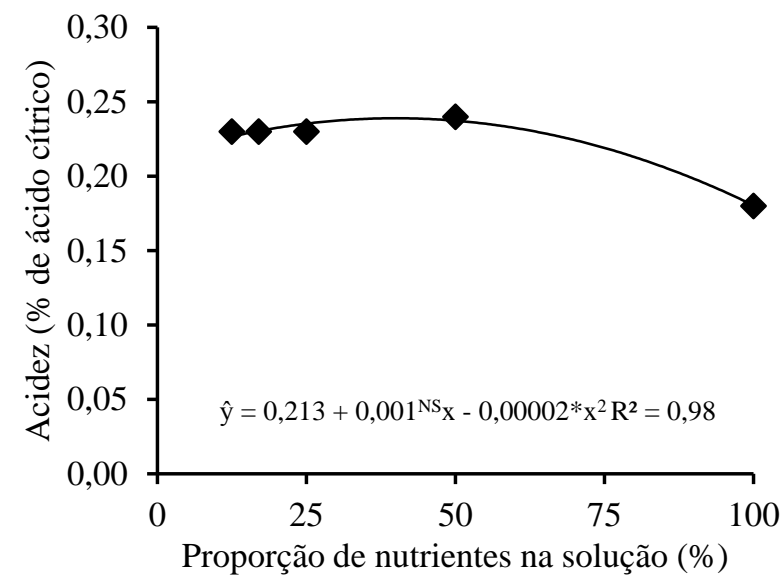

valores crescentes e constantes com o incremento da salinidade em função do manejo de nutrientes ministrados. No entanto, os índices de acidez titulável observado nos frutos de pepino do presente trabalho são superiores aos $0,16 \%$ observados por Medeiros et al. (2010) em cultivo com pepino híbrido Hokushin em ambiente salino.

B

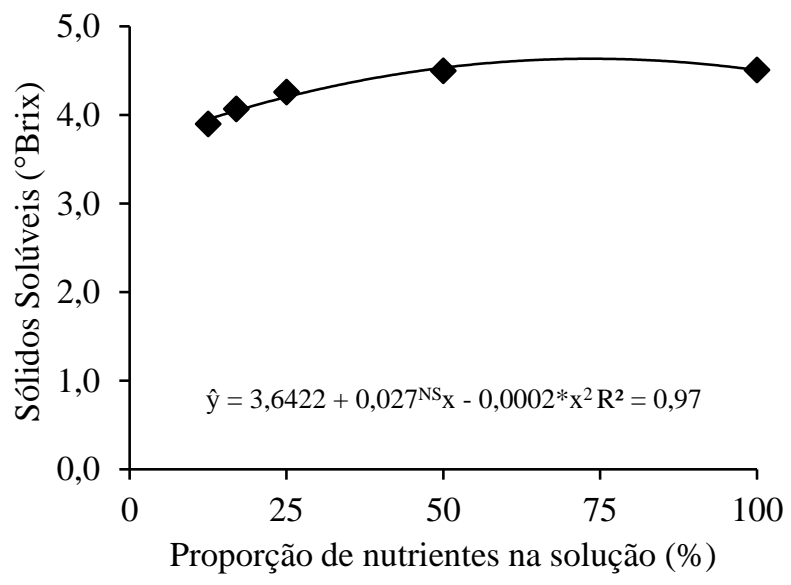

Figura 3. Acidez titulável (A) e sólidos solúveis (B) de frutos de pepino em função de proporções de nutrientes na solução nutritiva.

Os teores de sólidos solúveis $\left({ }^{\circ}\right.$ Brix $)$ ajustaram-se ao modelo quadrático, registrando-se acréscimos até a concentração de $67,5 \%$, correspondendo a 4,55 ${ }^{\circ}$ Brix máximo, com consequente decréscimo (Figura 3B). Resultados divergentes foram observados por Medeiros et al. (2010) ao verificarem efeito linear positivo para a variável sólidos solúveis totais em frutos de pepino (híbrido Hokushin) com o incremento da salinidade, sendo registrado como maior índice de sólidos solúveis $5,59^{\circ} \mathrm{Brix}$.

Os autores ainda relataram, que tal característica é explicada em função de que, para manter os níveis mais elevados de salinidade, são necessárias a aplicação quantidades elevadas de fertilizantes, consequentemente, maiores quantidades de sólidos.

Por outro lado, esses dados tem comportamento semelhante aos observadas por Dias et al. (2010) em melão rendilhado, que diminuiu a quantidade de sólidos solúveis totais com o aumento da concentração de sais na solução nutritiva em vasos contendo fibra de coco, ou seja, o estresse osmótico reduziu o conteúdo de sólidos solúveis dos frutos de meloeiro rendilhado.

Já Medeiros et al. (2008), estudando três níveis de salinidade de água de irrigação em campo, observaram efeito linear positivo sobre os SST dos frutos do meloeiro em virtude do incremento da salinidade.

De maneira geral, apesar de ter sido observado reduções na produção (Figuras $1 \mathrm{~A}$ e B) e características biométricas (Figuras 2A, B e C) dos frutos de pepino em função do aumento da concentração de nutrientes na solução, e consequentemente sua salinidade; os resultados encontrados estão dentro da faixa e/ou foram superiores aos resultados observados na literatura especializada (FERNANDES et al., 2002; MEDEIROS et al., 2010; PEDROSA et al. 2011; SEDIYAMA et al. 2012). Acrescenta-se que mesmo com essas reduções, o incremento de nutrientes na solução nutritiva até a proporção de $67,5 \%$ da solução padrão, melhorou a qualidade química dos frutos de pepino (cv. Caipira) (Figuras 3A e B). 


\section{CONCLUSÕES}

A redução da concentração de nutrientes na solução nutritiva padrão de $100 \%$ para $12,5 \%$ não afetou a produção do pepino.

As características biométricas peso médio, diâmetro longitudinal, espessura da poupa do fruto e a acidez titulável são reduzidos em função do aumento da condutividade elétrica de 1,0 para 3,8 $\mathrm{dS} \mathrm{m} \mathrm{m}^{-1}$.

A concentração de nutrientes na solução a $67,5 \%$ da solução nutritiva padrão, correspondente a $111,58 \mathrm{~g}$ de $\mathrm{N}-\mathrm{KNO}_{3}, 50,00 \mathrm{~g}$ de P-MAP, 62,44 $\mathrm{g}$ de $\mathrm{K}-\mathrm{KCl}, 241,50 \mathrm{~g}$ de $\mathrm{Ca}-\mathrm{CaNO}_{3}$ e $120,00 \mathrm{~g}$ de $\mathrm{Mg}-\mathrm{MgSO}_{4}$, prove produção satisfatória e frutos de pepino com melhor qualidade físico-química.

\section{REFERÊNCIAS}

CASTOLDI, R.; GOMES, R. F.; CHARLO, H. C. O.; MELO, D. M.; BRAZ, L. T. Performance of cucumber hybrids cultivated in coconut fiberand soil. Horticultura Brasileira, v. 32, n. 1, p. 86-90, $2014 . \quad$ http://dx.doi.org/10.1590/S010205362014000100014

DIAS, N. S.; LIRA, R. B.; BRITO, R. F.; SOUSA NETO, O. N.; FERREIRA NETO, M.; OLIVEIRA, A. M. Produção de melão rendilhado em sistema hidropônico com rejeito da dessalinização de água em solução nutritiva. Revista Brasileira de Engenharia Agrícola e Ambiental, v. 14, n. 7, p. 755-761, 2010. http://dx.doi.org/10.1590/S1415-

43662010000700011

DINIZ, A. A.; DIAS, N. S.; SOUZA, F. I.; SOUZA, A C. M.; MESQUITA, F. O.; SOUZA, F. I. Efeito da solução nutritiva sob o crescimento e composição mineral em pepino cultivado em substrato de fibra de coco. Semina: Ciências Agrárias, v 36, n. 5, p. 3043-3053, 2015. http://dx.doi.org/10.5433/1679-

0359.2015v36n5p3043

FERNANDES, A. A.; MARTINEZ, H. E. P.; OLIVEIRA, L. R. Produtividade, qualidade dos frutos e estado nutricional de plantas de pepino, cultivadas em hidroponia, em função das fontes de nutrientes. Horticultura Brasileira, v. 20, n. 4, p.
571-575, 2002. http://dx.doi.org/10.1590/S010205362002000400012

FERREIRA, D. F. Sisvar: a Guide for its Bootstrap procedures in multiple comparisons. Ciência e Agrotecnologia, Lavras, v. 38, n. 2, p. 109-112, $2014 . \quad \mathrm{http}: / /$ dx.doi.org/10.1590/S141370542014000200001

FILGUEIRA, F. A. R. Novo manual de olericultura: agrotecnologia moderna na produção e comercialização de hortaliças. 3.ed. rev. e ampl. Viçosa, MG: Editora UFV, 2013. 421p

FURLANI, P. R.; SILVEIRA, L. C. P.; BOLONHEZI, D.; FAQUIN, V. Cultivo hidropônico de plantas. Campinas: Instituto Agronômico, 1999. 52p. (Boletim Técnico, 180)

GENÚNCIO, G. C.; MAJEROWICZ, N.; ZONTA, E.; SANTOS, A. M.; GRACIA, D.; AHMED, C. R. M.; SILVA, M. G. Crescimento e produtividade do tomateiro em cultivo hidropônico NFT em fungos da concentração iônica da solução nutritiva. Horticultura Brasileira, v. 24, n. 2, p. 175-179, $2006 . \quad \mathrm{http}: / / \mathrm{dx}$. doi.org/10.1590/S010205362006000200010

IAL - Instituto Adolfo Lutz. Métodos físicoquímicos para análise de alimentos. 4. ed. São Paulo: IAL, 2008. 1018p

LINS, H. A.; ALBUQUERQUE, J. R. T.; QUEIROGA, R. C. F.; SÁ, F. V. S.; PEREIRA, A. M.; SILVA, A. B.; PAIVA, E. P. Biomass accumulation, plant biometrics and fruit production of watermelon according to changes in source/drain relations. Comunicata Scientiae, v. 7, n. 3, p. 272-279, 2016. https://doi.org/10.14295/cs.v7i3.1351

MEDEIROS J. F.; DIAS, N. S.; BARROS, A. D. Manejo da irrigação e tolerância do meloeiro a salinidade da água de irrigação. Revista Brasileira de Ciências Agrárias, v. 3, n. 3, p. 242-247, 2008. https://doi.org/10.5039/agraria.v3i3a264

MEDEIROS, P. R. F.; DUARTE, S. N.; DIAS, C. T. S.; SILVA, M. F. D. Tolerância do pepino à salinidade em ambiente protegido: Efeitos sobre propriedades físico-químicas dos frutos. Irriga, v. 
15, n. 3, p. 301-311, 2010. http://dx.doi.org/10.15809/irriga.2010v15n3p301

OLIVEIRA, F. A.; OLIVEIRA, M. K. T.; MEDEIROS, J. F.; PRAZERES, O. M.; PAIVA, E. P.; MAIA, P. M. E. Produtividade do maxixeiro cultivado em substrato e fertirrigado com soluções nutritivas. Horticultura Brasileira, v. 32, n. 4, p. 464-467, 2014. http://dx.doi.org/10.1590/S0102053620140000400015

OLIVEIRA, F. A.; SÁ, F. V. S.; PEREIRA, F. H. F.; ARAUJO, F. N.; PAIVA, E. P.; ALMEIDA, J. P. N. Comportamento fisiológico e crescimento de plantas de melancieira sob diferentes concentrações de solução nutritiva. Revista Brasileira de Agricultura Irrigada, v. 10, n. 3, p. 439-448, 2016. http://dx.doi.org/10.7127/rbai.v10n100365

OLIVEIRA, F. A.; SOUZA NETA, M. J.; MIRANDA, N. O.; SOUSA, A. A. T.; OLIVEIRA, M. K. T., SILVA, D. D. A. Strategies of fertigation with saline water for growing cucumber in a greenhouse. Revista Brasileira de Engenharia Agrícola e Ambiental, v. 21, n. 9, p. 606-610, $2017 . \quad \mathrm{http} / / / \mathrm{dx}$.doi.org/10.1590/18071929/agriambi.v21n9p606-610

PEDROSA, A. W.; MARTINEZ, H. E. P.; MARTIELLO, E. M.; FONTES, P. C. R.; PEREIRA, P. R. G. Influence of the $\mathrm{N} / \mathrm{K}$ ratio on the production and quality of cucumber in hydroponic system. Revista Ceres, v. 58, n. 5, p. 619-624, 2011. http://dx.doi.org/10.1590/S0034737X2011000500012

RINALDI, M. M.; SANDRI, D.; RIBEIRO, M. O.; AMARAL, A. G. Características físico-químicas e nutricionais de pimentão produzido em campo e hidroponia. Ciência e Tecnologia de Alimentos, v. 28, n. 3, p. 558-563, 2008. http://dx.doi.org/10.1590/S0101 -

20612008000300009

SÁ, F. V. S.; BRITO, M. E. B.; SILVA, L. A.; MOREIRA, R. C. L.; FERNANDES, P. D.; FIGUEIREDO, L. C. Fisiologia da percepção do estresse salino em híbridos de tangerineira-Sunki Comum sob solução hidropônica salinizada. Comunicata Scientiae, v. 6, n. 4, p. 463-470, 2015. http://dx.doi.org/10.14295/cs.v6i4.1121

SANTANA, M. J.; CARVALHO, J. A.; MIGUEL, D. S. Respostas de plantas de pepino à salinidade da água de irrigação. Global Science and Technology, v. 3, n. 3, p. 94-102, 2010

SEDIYAMA, M. A. N.; NASCIMENTO, J. L. M.; SANTOS, M. R.; VIDIGAL, S. M.; CARVALHO, I. P. L. Produção de pepino tipo japonês em ambiente protegido em função de adubação orgânica. Revista Brasileira de Agropecuária Sustentável, v. 2, n. 2, p. 65-74, 2012. http:// dx.doi.org/10.21206/rbas.v2i2.168 